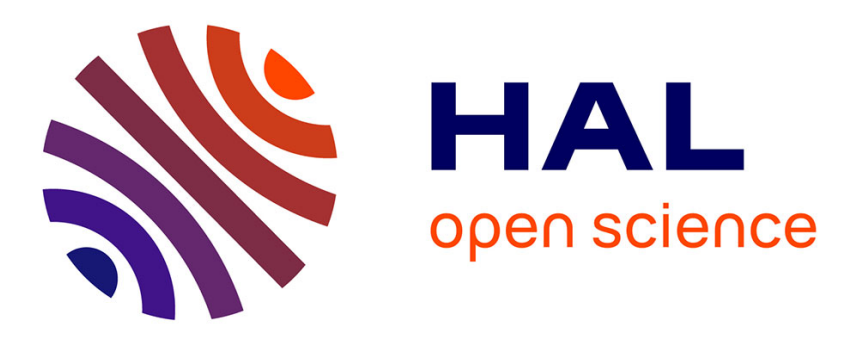

\title{
Assessment of forceps use in obstetrics during a simulated childbirth
}

Richard Moreau, Minh Tu Pham, Xavier Brun, Tanneguy Redarce, Olivier

Dupuis

\section{- To cite this version:}

Richard Moreau, Minh Tu Pham, Xavier Brun, Tanneguy Redarce, Olivier Dupuis. Assessment of forceps use in obstetrics during a simulated childbirth. The International Journal of Medical Robotics and Computer Assisted Surgery, 2008, 4 (4), pp.373-380. 10.1002/rcs.222 . hal-00368304

\section{HAL Id: hal-00368304 https://hal.science/hal-00368304}

Submitted on 8 Apr 2019

HAL is a multi-disciplinary open access archive for the deposit and dissemination of scientific research documents, whether they are published or not. The documents may come from teaching and research institutions in France or abroad, or from public or private research centers.
L'archive ouverte pluridisciplinaire HAL, est destinée au dépôt et à la diffusion de documents scientifiques de niveau recherche, publiés ou non, émanant des établissements d'enseignement et de recherche français ou étrangers, des laboratoires publics ou privés.

$$
\text { Copyright }
$$


International Journal of Medical Robotics and Computer Assisted Surgery

\section{Quantitative assessment of forceps use in obstetrics during a simulated childbirth}

\begin{tabular}{|c|c|}
\hline Journal: & $\begin{array}{l}\text { The International Journal of Medical Robotics and Computer } \\
\text { Assisted Surgery }\end{array}$ \\
\hline Manuscript ID: & RCS-08-0028 \\
\hline Wiley - Manuscript type: & Original Article \\
\hline $\begin{array}{l}\text { Date Submitted by the } \\
\text { Author: }\end{array}$ & 16-Jun-2008 \\
\hline Complete List of Authors: & $\begin{array}{l}\text { Moreau, Richard; Laboratoire Ampère, INSA-Lyon } \\
\text { Pham, Minh-Tu; Laboratoire Ampère, INSA-Lyon } \\
\text { Brun, Xavier; Laboratoire Ampère, INSA-Lyon } \\
\text { Redarce, Tanneguy; Laboratoire Ampère, INSA-Lyon } \\
\text { Dupuis, Olivier; CHU Lyon Sud, HCL }\end{array}$ \\
\hline Keyword: & $\begin{array}{l}\text { childbirth simulator, resident training, assessment manipulation, } \\
\text { mechatronic system }\end{array}$ \\
\hline
\end{tabular}

\section{s) ScholarONE" \\ Manuscript Central}




\title{
Assessment of the forceps use in obstetrics
}

\section{during a simulated childbirth}

\author{
R. Moreau*, M. T. Pham*, X. Brun*, T. Redarce* and O. Dupuis ${ }^{\dagger}$ \\ *Laboratoire Ampère, INSA-Lyon, F-69621 Villeurbanne Cedex, France \\ Email: richard.moreau@insa-lyon.fr,minh-tu.pham@insa-lyon.fr \\ Phone: +33472436212 Fax: +334724385 35 \\ ${ }^{\dagger}$ Hospices Civils de Lyon (HCL), CHU Lyon Sud, 69495 Pierre-Benite, France
}

\begin{abstract}
This paper provides a description of the BirthSIM simulator and its main features as a teaching tool in hospitals. More specifically, we focused on training with forceps during obstetric manipulation. The training method can be divided into two steps: on one hand the teaching of forceps placement and on the other hand the extraction manipulation. In this paper we focus on the extraction manipulation on the simulator. Experimental results reveal novice difficulty while proceeding to the fetus extraction. An evaluation function is computed to obtain a global score of the manipulation carried out by operators. Results lead to the conclusion that a simulator training offers benefit to novices by proposing them a risk-free training to acquire initial experience before proceeding to the traditional training in the delivery room.
\end{abstract}

\author{
Abstract: 128 words \\ Article text: $\approx 4900$ words \\ 14 double space pages \\ 2 tables \\ 5 figures
}




\section{INTRODUCTION}

Simulation tools are now essential in every area of activity (aerospace, automotive engineering, sport, etc.). Introducing simulator as a training tool in these areas of activity has enhanced performance and safety by extending professional skills.

In France, the level of perinatal mortality has remained constant since the 1980s [1]. This is due to the difficulty of acquiring knowledge and know-how in the delivery room. Obstetric training is therefore a practical issue. Obstetric manipulations and, in general, medical manipulations are still nowadays empirically acquired. However, it is difficult to assimilate properly such manipulations under constraints involving emergency and stressful conditions. Moreover in obstetrics, they are performed blindly (they take place inside the maternal body).

Simulators are relatively uncommon in hospitals, not only for structural reasons, e.g. cost or logistics, but also for reasons associated with medical profession habits. However, there are several types of childbirth simulator, which can be distinguished by their design:

- Anatomical simulators, featuring anthropomorphic manikins, are often used in midwifery and medical schools. Some of these simulators are commercially available.

- Virtual simulators make it possible to observe the path of the fetus through the pelvis [2]. Some of these simulators integrate haptic feedback systems [3].

- Instrumented anatomical simulators are much more attractive because they integrate functional characteristics of both the above types [4]-[6].

However, no anatomical instrumented simulators provide a complete training program. To fill this gap, Laboratoire Ampère has designed and developed a childbirth simulator called BirthSIM [5]. In the long term, this tool will ensure risk-free training of junior physicians and midwives and acquisition of initial experience prior to moving on to conventional delivery room training.

\section{Materials ANd Methods}

\section{A. The BirthSIM Simulator}

The primary aim of the BirthSIM simulator is to offer initial experience in eutocic childbirth (childbirth with no complications) by replicating the various forces involved and different birth situations. To be 
complete, this experience must be backed up by a training to instrumental childbirth, i.e. when obstetric instruments are necessary. The BirthSIM simulator integrates the following three distinct components to fulfill these objectives (Fig. 1).

- A mechanical component, which accurately reproduces the mother's pelvis and the fetal head to ensure continuity with delivery room training. The fetal head is instrumented with position and force sensors.

- An electro-pneumatic component, which ensures the delivery dynamic process by simulating uterine contractions, voluntary abdominal thrusts by the parturient (pregnant woman in the labor phase) and resisting force of the pelvic muscles.

- A visualization interface, which displays in real time the exact position of the fetal head and obstetrical instruments with respect to the mother's pelvis.

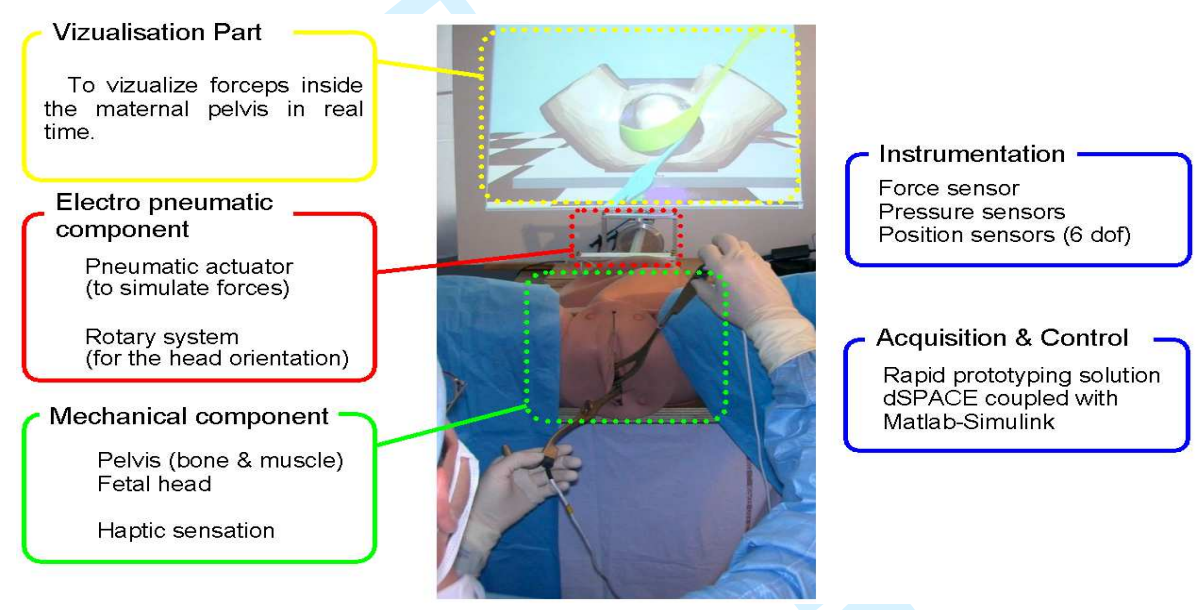

Fig. 1. The BirthSIM simulator.

The visualization interface displays also additional information. Thus not only fetal head position and operator force can be displayed but also the simulated childbirth parameters (frequency, amplitude, duration of parturient forces) (Fig. 2).

Several features are available on the BirthSIM simulator which make it a complete training tool. Indeed the BirthSIM offers a risk-free training to carry out the transvaginal diagnosis (to determine the position and the orientation of the fetal head inside the maternal pelvis). Once this diagnosis is validated by the instructor (the correct diagnosis can be displayed on the visualization interface), operator can 


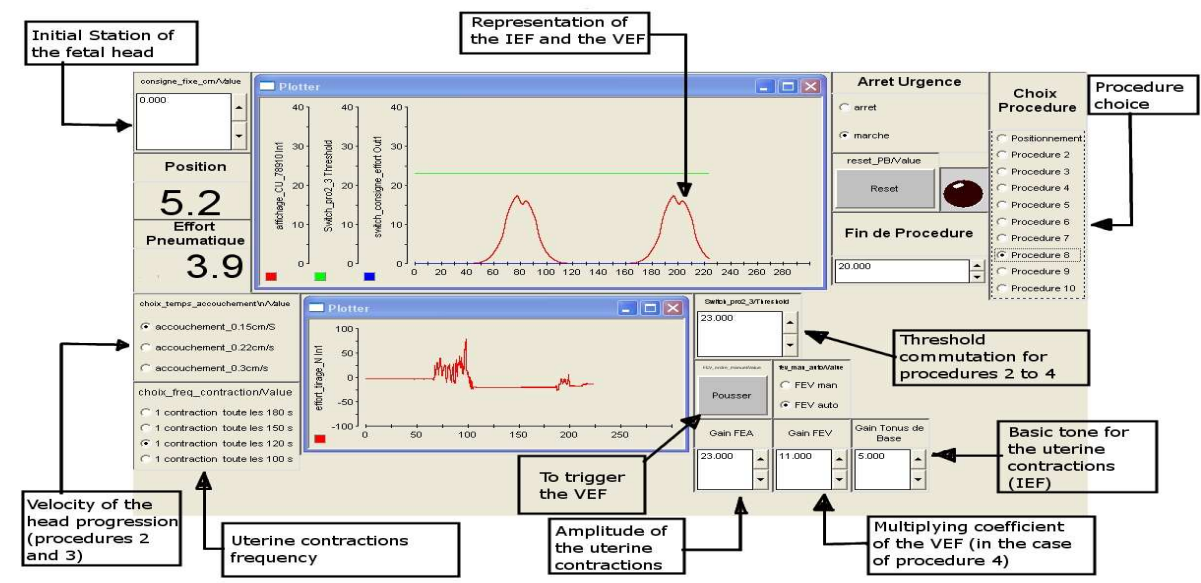

Fig. 2. Additional information which can be displayed on the visualization interface.

train to place its forceps on the fetal head. The training and the evaluation method are explained in subsection II-B. Finally, once the forceps are correctly placed, the operator can conclude the delivery by extracting the fetus. The pneumatic component which reproduces a realistic force feedback is described in subsection II-C.

\section{B. Forceps Blade Placement}

The mechanical component ensures a haptic interface to offer operators to have haptic sensations close to the reality and to use the same anatomical landmarks. The fetal head and the forceps are instrumented using electromagnetic sensors with the ability to measure the six degrees of freedom [7]. Such an instrumentation allows to study the fetal head and forceps displacement inside the maternal pelvis. It is thus possible to study the forceps blade placement carried out by operators and compared it to a placement carried out by an expert obstetrician. The forceps blade placement consists in placing the first blade (the blade hold by the left hand of the operator) through the pelvic canal. The blade actually has to "slide" between the fetal head and the pelvic muscles until reaching its final position i.e. when it's covering the ear and the jaw of the fetal head.

Based on the visualization interface, a training is proposed to junior obstetricians. Five specific points distributed regularly along the reference path are chosen to represent it. On the visualization interface, these points are the center of concentric spheres. Training involves passing though these spheres with the numerical models of the forceps blades in order to reproduce the reference placement (Fig. 3). 


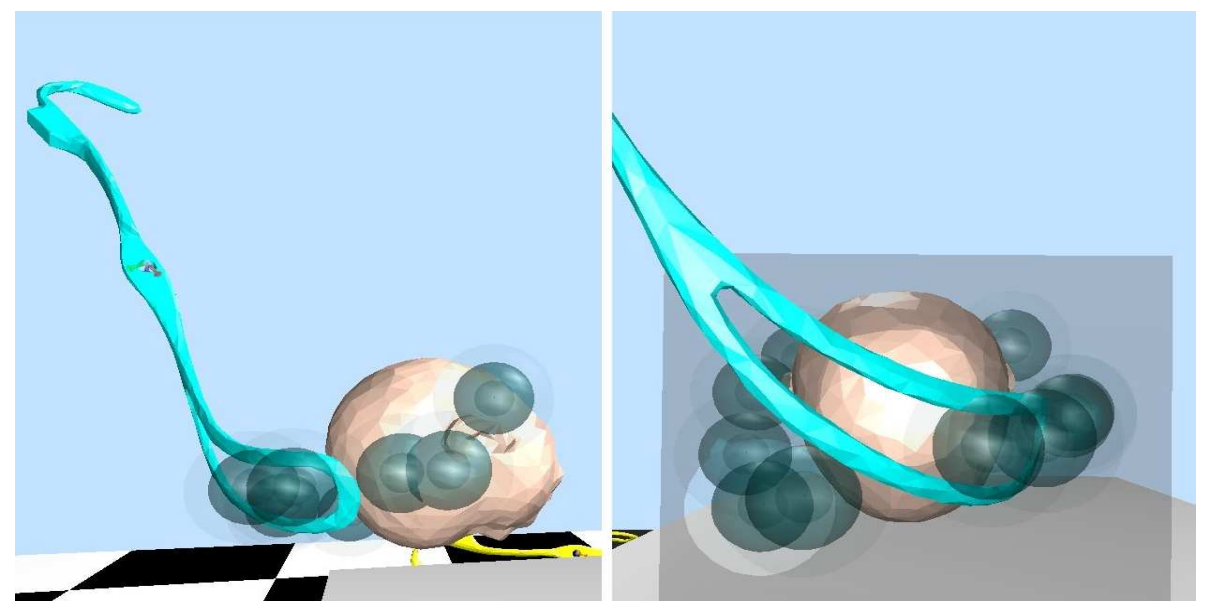

Fig. 3. Proposed training to reproduce the reference placement represented by the concentric spheres.

Once the forceps blade placement is carried out, they then perform the extraction manipulation.

\section{The Extraction Manipulation}

The aim of the forceps extraction is to help the mother if she did not manage to expel her fetus by herself. The electro-pneumatic component of the BirthSIM simulator replicates the different forces involved during a childbirth. Fig. 4 represents the scheme of the electro-pneumatic component. It consists of a servovalve which regulates the air flow in a pneumatic cylinder. Pressure sensors are mounted near each chamber of the pneumatic actuator. The system enables not only the fetal head to be positioned, but also the different childbirth-related forces to be simulated. A force sensor is mounted between the fetal head and the pneumatic actuator rod extremity to measure the force exerted on the fetal head by the operator.

The simulator provides ten procedures required by the medical team. These are based on position feedback control, velocity and force tracking control. Their implementation has been described in [8]. The originality of the system derives from the use of simple control laws to simulate different deliveries, allowing the operator to learn and train gradually. The objective is to enhance his attitude and reflexes during transvaginal diagnosis, when the parturient exerts abdominal thrust, and when he has to apply an additional force to expel the fetus with the forceps.

During a delivery, childbirth-related forces are:

- A resisting force from the pelvic muscles, which tend to prevent fetus progression within the pelvic 


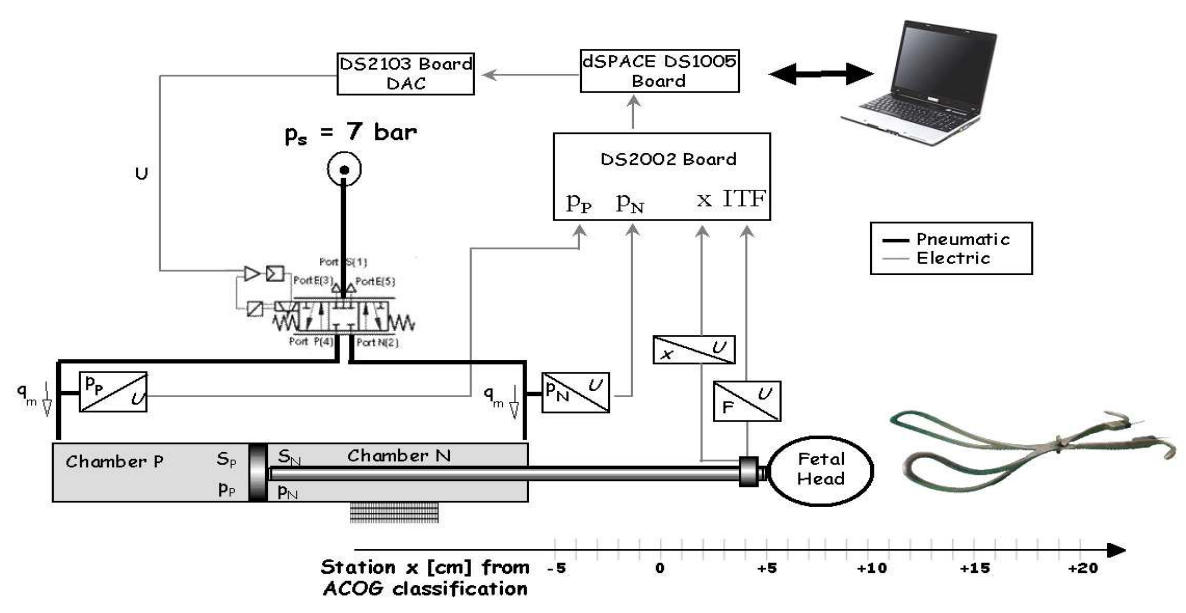

Fig. 4. Scheme of the electro-pneumatic component.

canal.

- Expelling forces originating from either:

- Uterine contractions, which are involuntarily produced by the parturient at regular frequency; these are the origin of the Involuntary Expulsive Force (IEF).

- Abdominal thrusts produced voluntarily by the parturient to expel the fetus. These expulsive forces are named Voluntary Expulsive Forces (VEF).

During eutocic childbirth, parturient forces (IEF and VEF) are sufficient to expel the fetus. The sum of the expulsive forces is called the Total Expulsive Force (TEF). In instrumental delivery cases $(11.2 \%$ of births in France in 2003 required the use of obstetrical instruments [9]), TEF is insufficient to ensure fetus expulsion. The medical team therefore has to complement TEF with an Instrumental Tractive Force (ITF) using instruments (forceps or vacuum extractor). This force must remain as small as possible to ensure the most natural birth. The objectives of the medical team are thus to synchronize these forces to optimize the TEF. A proper synchronization of the different expulsive forces are required to overcome the resisting force. Fig. 5 illustrates both poor and successful synchronization.

The notion of resistance threshold is very difficult to quantify and only close cooperation with experienced obstetricians can provide an estimate of its value. It depends on uterine and vaginal mechanical properties, which define the resisting force exerted by the organs on the fetus. In vivo measurements of this force during a childbirth is impossible for ethical and practical reasons. The tuning of the different 

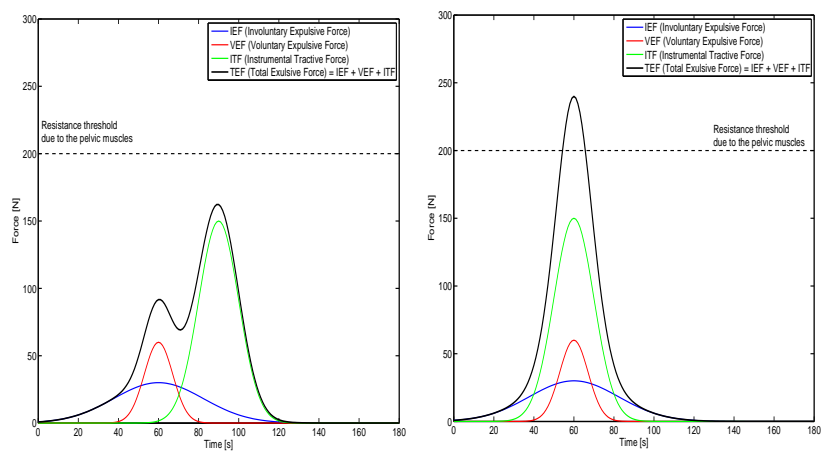

(a) Simple synchronization of the (b) Excellent synchronization: all IEF and the VEF but ITF is applied expulsive forces are synchronized too late

Fig. 5. Double synchronization concept

parameters of the control law has therefore been regulated based on senior obstetrician experience such that they perceive optimally the sensations which they are used to feel in delivery room.

\section{Experimental Protocol}

Four novice physicians were trained on the BirthSIM simulator. A novice obstetrician is a young obstetrician with less than twelve months obstetrical experience. The training was supervised by a senior obstetrician acting as instructor. A senior obstetrician is defined here as an obstetrician with more than ten years experience, who uses forceps in over $80 \%$ of its instrumented operations. Fetal head presentation was $\mathrm{OA}+2$ according to the ACOG classification (American College of Obstetrics and Gynecologists) [10]. OA means Occipito-Anterior location requiring forceps to be symmetrically placed. +2 means that the fetal head is at station +2 (two centimeters from the ischial spine plane) requiring forceps to be placed deep inside the mother's pelvis. The fetal head is considered as extracted from the mother's pelvis when it reaches station +15 , which triggers the end of the experiments.

The parturient was assumed to be over-tired and her expulsive forces are thus insufficient to ensure the fetus progression. An ITF was then necessary to complement parturient forces. This ITF had to be applied with a minimum intensity to limit the risks of complications, but with sufficient intensity to enable the fetus progression.

The synchronization concept was respected to minimize the ITF. Operators could follow the parturient IEF and VEF on a display monitor and they could therefore synchronize their ITF with parturient forces. 
The electro-pneumatic component of the BirthSIM simulator was set up to perform a "difficult" forceps extraction procedure.

The purpose of these experiments was to make novice physicians aware of childbirth-related forces and to offer them risk-free training in controlling the ITF they develop. The training session lasted about an hour, during which they performed ten extractions. It is possible to observe the evolution of the ITF they applied during training and to determine, for each novice physician, whether the ITF is sufficiently controlled before proceeding to a conventional delivery room training.

\section{RESULTS}

\section{A. Forceps Blade Placement Evaluation}

The forceps blade placement is not evaluated is this paper. It has already been studied in previous papers. The methods we developed allow to calculate the repeatability of an operator [11], its error compared to a reference manipulation defined by an expert [12] and a similarity measure based on a curvature analysis of the position and the orientation [13].

\section{B. The Extraction Manipulation Evaluation}

Concerning the force intensity applied by obstetricians during the extraction manipulation we already show that the results from experiments carried out on the BirthSIM simulator are within the range of the literature results [14]. Indeed Fleming [15] and Kelly [16] measured the maximum ITF intensity in vivo using dynamometer-instrumented forceps. They show that the ITF can reach 180 to $300 \mathrm{~N}$ depending on the difficulty of the extraction manipulation.

In the literature, only the maximal ITF is studied. Another advantage of a simulator training is also to allow the measure of the fetal head displacement during its extraction. Using data recorded not only by the force sensor but also by the position sensor of the fetal head, the study of the extraction manipulation can be complemented by taking into account the ITF work, denoted $I T F_{\text {work }}$, such as:

$$
I T F_{\text {work }}=\int_{0}^{t_{\text {end }}}|I T F(t) \cdot v(t)| d t
$$

where $t_{\text {end }}$ is the time needed by the obstetrician to complete its extraction manipulation and $v(t)$ is the velocity of the head during its extraction. 
The ITF mean value, denoted $I T F_{\text {mean }}$, is also calculated. It is the mean of the ITF intensity during the extraction manipulation until the fetal head is fully extracted (when it reached station +15 ).

An expert obstetrician, i.e. a senior obstetrician has also been recorded while extracting the fetus in order to carry out a "novice vs expert" comparison. The table I sums up the results concerning the ITF maximum intensity $\left(I T F_{m a x}\right)$, mean $\left(I T F_{\text {mean }}\right)$ and work $\left(I T F_{\text {work }}\right)$. The values are those obtained during the ten attempts operators carried out during the training.

TABLE I

Minimum, MAXIMUM, AND MEAN VALUES OF $I T F_{\text {max }}, I T F_{\text {mean }}$ AND $I T F_{\text {work }}$.

\begin{tabular}{||c||c||c|c|c||}
\hline \hline $\begin{array}{c}\text { Evaluation } \\
\text { Parameters }\end{array}$ & Operators & Value & $\begin{array}{c}\text { Malue } \\
\text { Value }\end{array}$ \\
\hline \hline \multirow{3}{*}{$\begin{array}{c}\text { Maximum } \\
\text { ITF } \\
\text { [N] }\end{array}$} & Novice 1 & 132 & 159.2 & 196 \\
\cline { 2 - 5 } & Novice 2 & 142 & 179.3 & 233 \\
\cline { 2 - 5 } & Novice 3 & 136 & 158.9 & 189 \\
\cline { 2 - 5 } & Novice 4 & 113 & 142.6 & 192 \\
\cline { 2 - 5 } & Expert & 104 & 130.4 & 166 \\
\hline \hline \multirow{3}{*}{$\begin{array}{c}\text { ITF } \\
\text { Work } \\
\text { [J] }\end{array}$} & Novice 1 & 13 & 15.4 & 17 \\
\cline { 2 - 5 } & Novice 2 & 14 & 18.3 & 22 \\
\cline { 2 - 5 } & Novice 3 & 12 & 15.6 & 21 \\
\cline { 2 - 5 } & Novice 4 & 12 & 14.6 & 20 \\
\cline { 2 - 5 } & Expert & 11 & 13.3 & 16 \\
\hline \hline \multirow{3}{*}{$\begin{array}{c}\text { Mean } \\
\text { ITF } \\
\text { [N] }\end{array}$} & Novice 1 & 37 & 57.9 & 79 \\
\cline { 2 - 5 } & Novice 2 & 31 & 54.8 & 90 \\
\cline { 2 - 5 } & Novice 3 & 29 & 42.7 & 60 \\
\cline { 2 - 5 } & Novice 4 & 34 & 49.7 & 75 \\
\cline { 2 - 5 } & Expert & 26 & 34.6 & 46 \\
\hline \hline
\end{tabular}

Concerning the minimum values obtained by novice operators, they are superior but for some novices they are near the expert ones. However they do not have enough experience to obtain mean and maximum values close to the expert ones. These facts may result in dramatic consequences during real deliveries.

To make the interpretation easier for the medical team, a global score of the manipulation has to be calculated. We thus propose to take into account not only the ITF (maximum and mean intensity and its work) but also other criterion. The position sensor in the head gives us informations on its displacement 
during the extraction manipulation. Indeed a simulator allows to have more data to analyze compared to a in vivo measurements. Thus the added evaluation criterion are:

1) The displacement of the fetal head is denoted Disp. It corresponds to the displacement of the fetal head due to the ITF exerted by the obstetrician including any back and forth displacement.

2) The time of the extraction manipulation is denoted $T$. It corresponds to the time needed by the obstetrician to complete its extraction manipulation.

3) The percentage of synchronization is denoted Synch. It corresponds to the percentage of synchronization between the different expulsive forces.

Extractions ensuring the safest delivery are obtained when values of $I T F_{\text {max }}, I T F_{\text {work }}, I T F_{\text {mean }}, T$, and Disp are minimum and the value of Synch is maximum. These evaluation parameters are then standardized between 1 and 10 for the first five parameters (the highest value obtained by novice physicians is ranked 10 and the lowest value obtained by senior physicians is ranked 1). The parameter Synch varies between 0.1 and 1 ( 0.1 is the lowest synchronization percentage value obtained by novice physicians and 1 is the highest synchronization percentage value obtained by senior physician). These standardizations allow then to compute an evaluation function in order to obtain one score taking into account all these parameters. The evaluation function is denoted $\mathrm{E}$ and it is defined by:

$$
E=\frac{\omega_{1}}{I T F_{\text {max }}}+\frac{\omega_{2}}{I T F_{\text {work }}}+\frac{\omega_{3}}{I T F_{\text {mean }}}+\frac{\omega_{4}}{\text { Disp }}+\frac{\omega_{5}}{T}+\omega_{6} \times \text { Synch }
$$

The terms $\omega_{i}$ ( $i$ from 1 to 6 ) are the weight coefficients for each parameter. Evaluation parameters were sorted according to their consequences for value assignment purposes. According to the medical team, the ITF developed causes major problems for the fetus or the parturient in terms either of its maximum intensity or its work. We therefore assign the highest coefficient for maximum ITF intensity and for the work it applies on the fetal head. The average ITF causes less significant consequences, and the value assigned to its weight coefficient is therefore lower. In decreasing consequence significance, we have the total head displacement, the synchronization percentage, and the manipulation time. For these parameters, the operator can follow the IEF on the monitor so both forces can easily be synchronized. Concerning manipulation time, the time required for fetus extraction is not a determining factor within the framework of this experiment (the objective of the experiments is an initiation to the extraction manipulation and 
not an emergency procedure simulation). The values assigned to these weight coefficients are:

$$
\left\{\begin{array}{l}
\omega_{1}=\omega_{2}=30 \\
\omega_{3}=20 \\
\omega_{4}=10 \\
\omega_{5}=\omega_{6}=5
\end{array}\right.
$$

The sum of these coefficients is 100; this enables us to obtain scores between 10 and 100 . An operator performs a good manipulation if he obtains a value close to 100 , i.e. all parameter values are close to the minimum values of the senior physician results (except for the synchronization percentage, which is a maximum).

It should be noted that these values can be modified according to the experiment required. For example, if an emergency procedure needs to be simulated, the manipulation time will be assigned a higher coefficient. In our case, the purpose is to extract the fetus with a minimal ITF intensity to curtail the risk for both the fetus and the parturient.

This evaluation function allows to study the behavior of the operators according to the selected criteria. The maximum, the minimum the mean and the standard deviation (SD) of the evaluation function for ten extraction manipulations are computed and the results are summed up in the following table (Table II).

TABLE II

RESULTS OF THE EVALUATION FUNCTION

\begin{tabular}{||l|c|c|c|c||c||}
\cline { 2 - 6 } \multicolumn{1}{c|}{} & Novice 1 & Novice 2 & Novice 3 & Novice 4 & Expert \\
\hline \hline Maximum & 47.8 & 57.2 & 62.4 & 76.8 & 83.3 \\
\hline Minimum & 31.5 & 20 & 25.4 & 26.9 & 41 \\
\hline Mean & 39.5 & 32.4 & 41.6 & 51.2 & 61.4 \\
\hline SD & 5.6 & 11.2 & 11.8 & 17.2 & 16.6 \\
\hline \hline
\end{tabular}

First, we can notice that novice results are quite disperse which lead to say that they need a personalized training. This personalized training can be carried out on the simulator whereas during the classical training in the delivery rooom this kind of training can not be ensured. The evaluation function also highlights the difference between expert and novices especially concerning the mean value of the evaluation function. Expert mean score is 61.4 whereas novice's mean score is between 32.4 and 51.2 . 
Novice 4 manages to master its extraction manipulation as shows its maximum score (76.8) close to the expert one (83.3). Other novices need to continue training on the BirthSIM simulator before proceeding to an extraction manipulation in the delivery room.

\section{CONCLUSION}

This paper provides an overview of the different features available on the BirthSIM simulator and the clinical results obtained while training novice physicians. Training is divided into two stages. The first stage is to allow novice physicians to place correctly the forceps. In this paper we focus on the second stage : the extraction manipulation. It was possible to record the force exerted by a novice physician by instrumenting the fetal head with a force sensor. Concerning the forces exerted by operators to extract the fetus, the results obtained are in the same range than the in vivo results which confirms the realism of our simulator concerning the force feedback while simulating a forceps extraction manipulation.

In order to complete the evaluation of the extraction manipulation, other criterion are taken into account such as the head displacement and the synchronization percentage between the expulsive force exerted by an operator and the parturient expulsive force. This highlights another advantage of a childbirth simulator which allows not only a risk-free training but also a complementary instrumentation of the fetus.

An evaluation function is then computed to take into account several parameters as proposed in [17] where a suture/ligature simulator allows to evaluate residents. This function enables us to calculate a global performance score and thus to quantify novice physician skills and ability. With simulator training, novice physicians become aware of the force amplitude involved during instrumental delivery and they can try to control their ITF under risk-free conditions. One of the interest of such an evaluation function is the opportunity to reverse the calculation to study which criterion are responsible of a poor score. In our case, for example, the ITF maximum intensity is responsible of the poor score obtained by novice 2 . He can thus try to improve his manipulation in order to increase his score. It is also possible to change the values of the weight coefficients of the function if needed. For example if the instructor wants to evaluate an emergency procedure the time of the extraction manipulation can be affected to the highest weight coefficient value.

The BirthSIM simulator is a tool for training novice obstetricians by providing them the opportunity to overcome the conventional training-related constraints. Proposed training allows novice obstetricians 
to acquire initial experience by performing obstetric manipulations. The aim of the simulator training is not to substitute the traditional training in the delivery room but to complement it.

Initial results are encouraging but they must be complemented by further training sessions with more novice physicians to obtain more representative results. A new campaign of measurements has just begun at a hospital (Centre Hospitalier Universitaire Lyon Sud) with the last prototype of the BirthSIM simulator.

\section{REFERENCES}

[1] B. Blondel, J. Norton, C. Dumazaubrun, and G. Breart. Enquête Nationale Périnatale 1998. Technical report, Direction Générale de la Santé, Paris, France, 2000.

[2] J. D. Boissonnat and B. Geiger. 3D simulation of delivery. In Nielson G. Bergeron D., editor, Visualization 93 Conference, pages 416-419. Computer Society Press Editors, San Jose, CA, USA, October 1993.

[3] A. Kheddar, C. Devine, M. Brunel, C. Duriez, and O. Sibony. Preliminary design of a childbirth simulator haptic feedback. In IEEE/RSJ International Conference on Intelligent Robots and Systems, (IROS'04), volume 4, pages 3270-3275, 28 Sept.-2 Oct. 2004.

[4] T. Sielhorst, T. Obst, R. Burgkart, R. Riener, and N. Navab. An augmented reality delivery simulator for medical training. In Augmented environments for Medical Imaging including Augmented Reality in Computer-aided Surgery (AMI ARCS'04), pages 11-20, Rennes, France, 2004.

[5] R. Silveira, M. T. Pham, T. Redarce, M. Betemps, and O. Dupuis. A new mechanical birth simulator: BirthSIM. In IEEE/RSJ International Conference on Intelligent Robots and Systems, (IROS'04), volume 4, pages 3948-3953, 28 Sept.-2 Oct. 2004.

[6] E. J. Kim, P. Theprungsirikul, M. K. McDonald, E. D. Gurewithsch, and R. H. Allen. A biofidelic birthing simulator. IEEE Engineering in Medicine and Biology Magazine, 24(6):34-39, Nov.-Dec. 2005.

[7] R. Moreau, M. T. Pham, R. Silveira, T. Redarce, X. Brun, and O. Dupuis. Design of a new instrumented forceps: Application to safe obstetrical forceps blade placement. IEEE Transactions on Biomedical Engineering, 54(7):1280-1290, July 2007.

[8] O. Olaby, R. Moreau, X. Brun, O. Dupuis, and T. Redarce. Automatic childbirth procedures implanted on the BirthSIM simulator. In IEEE/RSJ International Conference on Intelligent Robots and Systems (IROS'06), pages 2370-2375, Beijing, China, 2006.

[9] O. Dupuis, R. Silveira, T. Redarce, A. Dittmar, and R.-C. Rudigoz. Operative vaginal delivery rate and neonatal associated complications in 2002 in the AURORE hospital network. Gynécologie Obstétrique et Fertilité, 31(11):920-926, 2003.

[10] G. Cunningham, L. Gilstrap, K. Leveno, S. Bloom, J. Hauth, and K. Wenstrom. Williams Obstetrics. the McGraw-Hill Companies, $22^{\text {nd }}$ edition, 2005. ISBN 0071413154.

[11] R. Moreau, O. Olaby, O. Dupuis, M. T. Pham, and T. Redarce. Paths analysis for a safe forceps blades placement on the BirthSIM simulator. In IEEE International Conference on Robotics and Automation (ICRA'06), pages 739-744, Orlando, USA, May 15-19, 2006.

[12] R. Moreau, A. Jardin, M. T. Pham, T. Redarce, O. Olaby, and O. Dupuis. A new kind of training for obstetric residents: simulator training. In $28^{\text {th }}$ Annual International Conference of the IEEE Engineering in Medicine and Biology Society (EMBC '06), pages 4416-4419, New-York, USA, Aug. 2006. 
[13] R. Moreau, V. Ochoa, M.T. Pham, P. Boulanger, T. Redarce, and O. Dupuis. A method to evaluate skill transfer and acquisition of obstetric gestures based on the curvatures analysis of the position and the orientation. Elsevier, Journal of Biomedical Informatics, page In Press, 2008.

[14] R. Moreau, M. T. Pham, T. Redarce, and O. Dupuis. Simulation of forceps extraction using the childbirth simulator BirthSIM. In IEEE International Conference on Robotics and Automation (ICRA'08), pages 1100-1105, Pasadena, USA, 19-23 May 2008.

[15] A. R. Fleming, K. R. Brandeberry, and W. H. Pearse. Introduction of a metric forceps. American Journal of Obstetrics and Gynecology (AJOG), 78:125-133, 1959.

[16] J. V. Kelly and G. Sines. An assessment of the compression and traction forces of obstetrical forceps. American Journal of Obstetrics and Gynecology (AJOG), 96:521-537, 1966.

[17] N. Oshima, M. Aizudding, R. Midorikawa, J. Solis, Y. Ogura, and A. Takanishi. Developement of a suture/ligature training system designed to provide quantitative information of the learning progress of trainees. In IEEE International Conference on Robotics and Automation (ICRA'07), pages 2285-2291, Roma, Italy, 10-14 April 2007. 